The blood supply to the lower limb bones in man By Henry V. Crock. Pp. viii +104 , illustrated. Edinburgh and London : E. \& S. Livingstone. 1967. $£ 5$ s.

The vascular anatomy of bone is a subject whose importance is becoming increasingly realized. In order to understand normal function and such pathological processes as osteoarthritis we need precise knowledge not only of the arterial supply to bone but also the detail of its venous drainage. The author's extensive researches have equipped him to provide this information and he has achieved his purpose admirably.

The book is a model of what a monograph should be. It is clearly written, splendidly produced and most beautifully illustrated with a wealth of colour plates. The author is to be congratulated on a work which anatomists and surgeons will find a joy to handle and from which they will learn much.

\section{Psychopathic disorders and their assessment}

Edited by M. Craft. Pp. $x+320$. Oxford : Pergamon Press. 1966. 50s.

This is an excellent small book. The problems surrounding our understanding of psychopathy are illuminated in a succession of chapters by ten people, mostly psychiatrists and psychologists, who are outstanding in this country for their experience in the field.

Dr Craft, the editor, contributes four chapters himself on aetiological, descriptive, clinical and therapeutic aspects of psychopathy. Dr Gibbens provides an excellent chapter concerned with the social dilemma and the confused thinking surrounding society's attempts to help the offending psychopath. Other writers discuss the social and legal problems and special investigatory techniques. With reference to the latter there is an extensive appendix concerned to cover the whole spectrum of psychological methods of assessment. Although this is interestingly written and of some specific as well as general applicability, this book hardly seems the place for such an extensive review. There is a soft cover cheaper version of the book under the title Psychopathic Disorders which does not contain the appendix.

\section{Pathology of the kidney}

By Robert H. Heptinstall. Pp. $x+836$, illustrated. London : J. \& A. Churchill. 1966. 200s.

This volume will undoubtedly become a standard in the field and at last fills a longstanding gap in texts on renal pathology that has existed since the writings of Volhard and Fahr. It is written in a clear, forthright manner and is extremely well illustrated. The author is never dogmatic, and his treatment of other work is skilful and painstaking, as might be expected of such an expert investigator and pathologist. One may not agree with all his views, for example the specificity of the renal lesion in post-streptoccocal glomerulonephritis, but the evidence on which they are based is clearly presented affording the critical reader of an alternative viewpoint. He highlights the many difficult and as yet unanswered problems in the renal field. Characteristic of an experienced researcher, he suggests how modern techniques and where further follow up clinical evaluation may help in the elucidation of these matters.

This book not only deals with renal disease from a pure pathological standpoint but also presents a masterful integration of historical, clinical and experimental data to support the pathological evidence. Where possible the author has striven to match the clinical evolution of renal disease processes with serial biopsy and autopsy material. Further, much to his credit, the author has attempted to do what others have chosen to ignore, that is to rationalize nomenclature concerning renal disease. This is particularly well brought out in his chapters on glomerulonephritis. The whole volume is carefully balanced so that space given to the pathology of renal diseases is proportionate to their clinical frequency. Nevertheless, there is ample coverage of the rarer renal disorders. Two well-known invited authors have written valuable sections on development of the kidney and congenital malformations and on renal transplantation. These sections give an up-to-date discussion of these two important and rapidly progressive fields.

Each chapter in this book is followed by a complete and fairly exhaustive list of references and there is a good index. This volume will be much sought after by pathologists, researchers in the renal field, urologists and nephrologists alike. There is no other modern volume that gives such a comprehensive review of the subject.

\section{Modern trends in rheumatology}

Edited by Alan G. S. Hill. Pp. ix +394 , illustrated. London : Butterworths. 1966. 95s.

This is an excellent book; Dr Alan Hill and his distinguished team of contributors are to be congratulated. With the swift expansion of knowledge clinicians find it harder each year to keep abreast of developments outside their own field: the Modern Trends series helps to remedy this and it is timely that a volume is devoted to rheumatology.

Each chapter is more than a review of a subject or topic, the authors have been chosen carefully because of personal research contributions and critical approach. It is difficult to single out any particular chapter-most topics are covered; but certain ones have important information for readers at any stage of career. The epidemiology of rheumatic disease by Dr John Lawrence is basic and must serve as a yardstick for many studies to come. Autoimmunity and its role is covered clearly and well by $\operatorname{Dr} J$. R. Anderson and Dr W. Watson Buchanan, and Dr D. J. McCarthy has presented a fine account of crystal induced arthritis. Dr J. H. Talbot on gout is excellent; however, it is surprising in a book on modern trends that Allopurinol, Anturan and Indomethacin are not mentioned in treatment. The chapter on polymyositis and dermatomyositis is good, obviously Dr Carl Pearson has seen much material but an important diagnostic aid to muscle disease is the electromyograph: motor unit mean potential duration and potential counting are not mentioned; both of these give a quantitative estimate of myopathy complementing the muscle enzymes.

No book of this size can cover every aspect of disease, that is not its function; nevertheless, a section on corticosteroids and immunosupressives would have been welcome and it is a pity that $\operatorname{Dr}$ A. J. Popert's brief was not wider than his highly competent account of gold and antimalarials.

Throughout the book the quantity and quality of information is of the highest order, clearly presented and with plenty of up-to-date references. It will be a welcome newcomer to be read with enjoyment even if it keeps up with other modern trends at $95 \mathrm{~s}$., substantially more than its nearest rival.

\section{A summary of psychiatry}

By Alexander Elkes and J. G. Thorpe. Pp. 143. London : Faber \& Faber. 1967. 13s 6d.

The best that can be said of this book is that it does not take long to read. Much of the content is easy to read although often badly written. Subjects are dealt with in an unsystematic way. The majority of psychiatric disorders are touched on descriptively as are the main classificatory and therapeutic approaches; some final sections contain patchy information on legal, administrative and social aspects of psychiatry. It is probably the author's aim of brevity which has sometimes put them in the position of seeming to make unwarranted assertions about the value of specific treatments. 